\title{
Effects of in vivo administration of epidermal growth factor (EGF) on uterine contractility, prostaglandin production and timing of parturition in rats
}

\author{
M. L. Ribeiro, M. Farina, J. Aisemberg and A. Franchi \\ Laboratorio de Fisio-patología de la Preñez y el Parto, Centro de Estudios Farmacológicos y Botánicos \\ (CEFYBO, CONICET), Serrano 669, 3rd Floor, C1414DEM, Bs. As. Argentina
}

\begin{abstract}
Prostaglandins synthesized by cyclooxygenases elicit uterine contractions during labour. Nitric oxide synthases (NOS) produce nitric oxide (NO), which maintains uterine quiescence during pregnancy. Epidermal growth factor (EGF) interacts with prostaglandins and NO in many biological systems. The aim of this work was to study the effect of the in vivo administration of EGF on uterine contractility, prostaglandin production and timing of parturition in rats. EGF was injected into the uterine lumen of pregnant rats on day 20, 21 or 22 of gestation. Intra-uterine administration of $500 \mathrm{ng}$ EGF on day 21 of gestation delayed parturition for $18 \mathrm{~h}$ compared with control rats. Administration of EGF was able to: (i) reduce
\end{abstract}

cyclooxygenase expression in the uterus (determined by western blot analysis) and production of prostaglandins by the uterus (evaluated by conversion of $\left[{ }^{14} \mathrm{C}\right]$ arachidonate to labelled prostaglandins); (ii) decrease prostaglandin concentrations in amniotic fluid (radioimmunoassay); (iii) increase NO production (evaluated by conversion of $\left[{ }^{14} \mathrm{C}\right]$ arginine into $\left[{ }^{14} \mathrm{C}\right]$ citrulline); (iv) increase serum progesterone concentrations to more than control concentrations $(P<0.05$; radioimmunoassay); and (v) reduce the amplitude of the uterine contractions. The overall effect was a delay in the onset of delivery. This in vivo effect raises the question of whether exogenous EGF plays a role in the initiation of parturition.

\section{Introduction}

Most studies of epidermal growth factor (EGF) have focused on the stimulation of cell proliferation. However, EGF appears to have other biological activities. Cohen (1962) showed that EGF accelerated incisor eruption and eyelid opening in immature mice. In addition, EGF plays a role in fetoplacental growth and development by increasing hormone secretion by placental and fetal membranes (Maruo et al., 1987). In rodents, physiological concentrations of EGF induce contractions of oestrogen-primed uterine smooth muscle in vitro (Gardner et al., 1987). These observations may be indicative of previously unrecognized roles for EGF in the control of differentiated functions. It is now becoming clear that EGF may have a role during pregnancy and labour. Tamada et al. (2000) found that intraluminal infusion of EGF into goat uterine horns gradually reduced the uterine activity at either oestrus or dioestrus. EGF has been found in several reproductive tissues including the uterus and placenta of women (Richards et al., 1983; Lin et al., 1988), rodents (Huet-Hudson et al., 1990), pigs (Vaughan et al., 1992) and sheep (Lacroix and Kann, 1993). EGF is also present in maternal and fetal blood, and in amniotic fluid (Ances, 1973; Barka et al., 1978),

Email: marialribeiro@yahoo.com.ar in which its concentration correlates with progression of pregnancy (Varner et al., 1996). Das et al. (1994) found in pregnant mice two classes of binding sites for EGF, which are regulated by oestradiol and progesterone.

Prostaglandins and nitric oxide (NO) are intimately involved in the mechanism of parturition (Mitchell et al., 1995; Farina et al., 2001). NO maintains uterine quiescence during pregnancy (Yallampalli et al., 1993), whereas prostaglandins are involved in eliciting contractions of uterine smooth muscle (Franchi et al., 1994). Prostaglandins are active lipid mediators involved in the mechanism of parturition. Prostaglandin biosynthesis is catalysed by cyclooxygenase. Cyclooxygenase exists in two isoforms: cyclooxygenase 1 and cyclooxygenase 2 (Kujubu et al., 1991; Simmons et al., 1993). NO is synthesized by nitric oxide synthase (NOS; Norman and Cameron, 1996). Three NOS isoforms involved in pregnancy have been characterized: endothelial nitric oxide synthase (eNOS), neuronal nitric oxide synthase (nNOS) and inducible nitric oxide synthase (iNOS) (Yallampalli et al., 1994; Farina et al., 2001). EGF regulates both prostaglandins and $\mathrm{NO}$ in reproductive tissues. EGF stimulates $\mathrm{PGE}_{2}$ synthesis and cyclooxygenase 2 expression in human amnion cells in a time-dependent way (Mitchell, 1987; Casey et al., 1988). EGF also produces uterine contractions in tissues removed from immature and adult rats (Gardner et al., 1987), and 
this effect is dependent on prostaglandin production and entry of calcium into the cells (Gardner and Stancel, 1989). Ribeiro et al. (1999) reported an effect of EGF on NO synthesis: incubation of oestrogenized rat uterus with EGF augmented NO synthesis by stimulating iNOS activity. In addition, it is possible that NO and prostaglandins could interact in different tissues (Salvemini et al., 1996; Perkins and Kniss, 1999).

On the basis of the evidence presented above, the aim of the present study was to investigate the effect of exogenous administration of EGF on uterine contractility, prostaglandin production and timing of parturition in rats.

\section{Materials and Methods}

\section{Materials}

EGF (murine submaxillar glands, culture grade, $\mathrm{PM}=6100$ ) was from Calbiochem (Norabiochem Corporation, La Jolla, CA). $\left[{ }^{14} \mathrm{C}\right]$ arachidonic acid $\left(56 \mu \mathrm{Ci} \mathrm{mmol}^{-1}\right), \quad\left[{ }^{14} \mathrm{C}\right] \mathrm{L}$-arginine monohydrocloride $\left(317 \mathrm{mCi} \mathrm{mmol}^{-1}\right), \quad\left[5,6,8,9,11,12,14,15(\mathrm{n})-{ }^{3} \mathrm{H}\right] \mathrm{PGF}_{2 \alpha}$ $\left(160 \mathrm{Ci} \mathrm{mmol}^{-1}\right), \quad\left[5,6,8,9,11,12,14,15(\mathrm{n}){ }^{3} \mathrm{H}\right] \mathrm{PGE}_{2}$ $\left(130 \mathrm{Ci} \mathrm{mmol}^{-1}\right)$ and $17 \alpha$-hydroxy $\left[1,2,6,7-{ }^{3} \mathrm{H}\right]$ progesterone $\left(60 \mathrm{Ci} \mathrm{mmol}^{-1}\right)$ were from Amersham Corporation (Arlington Heights, IL). Dowex AG500-X column $\left(\mathrm{Na}^{+}\right.$-form) was from BioRad (Alfatron, SRL, Buenos Aires). Monoclonal nNOS, eNOS and iNOS first antibodies were from Transduction Co. (Lexington, KY), whereas monoclonal cyclooxygenase 1 and polyclonal cyclooxygenase 2 were from Santa Cruz Biotechnology Inc. (Copenhagen). $\mathrm{PGE}_{2}$ and $\mathrm{PGF}_{2 \alpha}$ antiserum and second antibodies were purchased from Sigma Chemical Co. (St Louis, MO). Progesterone antiserum was provided by G. D. Niswender (Colorado State University, Fort Collins, CO). All other chemicals were of analytical grade.

\section{Animals}

The experimental procedures were approved by the Animal Care Committee of the Center of Experimental Pharmacology and Botany of the National Research Council (CEFYBO-CONICET) and carried out in accordance with the Declaration of Helsinki.

Wistar rats were housed in group cages (six in each cage) under controlled conditions of light (14 h light:10 h dark) and temperature $\left(23-25^{\circ} \mathrm{C}\right)$. Food and water were available ad libitum. Time-mated pregnant rats of the Wistar strain (200-300 g body weight) were used. The morning on which spermatozoa were observed in the vaginal fluid was defined as day 1 of pregnancy. Spontaneous term labour usually occurs on day 22 of gestation.

\section{Intra-uterine administration of EGF}

The pregnant rats were given a single intra-uterine injection of EGF on day 20, 21 or 22 of gestation with a single dose of EGF to determine whether in vivo administration of EGF modulates the onset of parturition. The doses administered were 15, 30, 60, 120, 250 or $500 \mathrm{ng}$ EGF (final volume: $250 \mu \mathrm{l})$. Control rats received an intra-uterine injection of saline solution (EGF vehicle; $250 \mu \mathrm{l}$ ) on day 20,21 or 22 of gestation. Control and treated animals were anaesthetized by ether inhalation and the intra-uterine injections (gauge needle: 30G) were conducted under direct visualization of the uterine horns. The uterus of each rat was surgically exposed and the injection was given inside the uterine lumen. After injection, the rats were housed in separate cages and were monitored continuously for pups. Day and time of parturition were registered when the first pup was delivered. The values were expressed as the mean variation in the onset of parturition (in hours) compared with control rats (control rats gave birth on day 22 at approximately 20:00 h). The handling of the rats did not have any effect on the onset of parturition as rats injected with saline solution on day 20,21 or 22 of gestation gave birth normally on day 22 .

The effects of EGF administration on the mother and the pups were evaluated grossly by observing activity, feeding and general wellbeing. The rats were killed on day 22 of gestation between 10:00 h and 11:00 h. The amniotic fluid and uterine horns were extracted, cleaned of fat, placenta and fetuses, and stored at $-70^{\circ} \mathrm{C}$ until used. The part of the uterine horn used in each experiment was selected randomly and was independent of the site of injection.

\section{Metabolism of $\left[{ }^{14}\right.$ C]arachidonic acid}

Uterine tissues from EGF-treated and control rats were placed in Petri dishes containing a modified Kreb'sRinger bicarbonate (KRB) solution $\left(145 \mathrm{mmol} \mathrm{Na}^{+} \mathrm{I}^{-1}\right.$; $6 \mathrm{mmol} \mathrm{K} \mathrm{I}^{-1} ; 2 \mathrm{mmol} \mathrm{Ca}{ }^{2+} \mathrm{I}^{-1} ; 1.3 \mathrm{mmol} \mathrm{Mg}^{2+} \mathrm{I}^{-1}$; $126.1 \mathrm{mmol} \mathrm{Cl}^{-} \mathrm{I}^{-1} ; 25.3 \mathrm{mmol} \mathrm{HCO}_{3}^{-} \mathrm{I}^{-1} ; 1.3 \mathrm{mmol}$ $\mathrm{SO}_{4}^{2-\mathrm{I}^{-1}} ; 1.2 \mathrm{mmol} \mathrm{PO}_{4}^{2-} \mathrm{I}^{-1} ; 11 \mathrm{mmol}$ glucose $\mathrm{I}^{-1}$ ). The tissues were then weighed. The metabolism of exogenous arachidonic acid was determined by incubating the tissues for $1 \mathrm{~h}$ in KRB medium containing $50 \mu \mathrm{Ci}\left[{ }^{14} \mathrm{C}\right.$ arachidonic acid $\mathrm{ml}^{-1}$ in an atmosphere of $95 \% \mathrm{O}_{2}$ and $5 \% \mathrm{CO}_{2}$ at $37^{\circ} \mathrm{C}$. At the end of the incubation period, the medium was acidified to $\mathrm{pH} 3$ using $1 \mathrm{~N} \mathrm{HCl}$ in 1 volume of ethyl acetate and extracted twice for prostaglandins. Pooled ethyl acetate extracts were dried. The residues were suspended in $100 \mu \mathrm{l}$ methanol and applied to silica gel TLC plates. The plates were developed in a solvent system of benzene:dioxane:glacial acetic acid (60:30:3; v/v). The positions of the authentic prostaglandins were determined by liquid scintillation counting. The area of each radioactive peak corresponding to an authentic prostaglandin was calculated and expressed as a percentage of the total radioactivity of the plates. Only results in which metabolites were converted in more 
than $1 \%$ of c.p.m. on TLC plate were considered. Enzyme activity is reported as \% c.p.m. in total plate (100 mg wet weight) ${ }^{-1}$.

\section{Total NOS assay}

NOS activity was quantified using a modified method of Bredt and Snyder (1987), which measures the conversion of $\left[{ }^{14} \mathrm{C}\right] \mathrm{L}$-arginine into $\left[{ }^{14} \mathrm{C}\right] \mathrm{L}$-citrulline. $\mathrm{NO}$ and L-citrulline are produced in equimolar amounts. EGF-treated and control uterine horns were weighed, homogenized (Ultra Turrax, T25 basic; IKA Labortechnik, Staufen) and incubated at $37^{\circ} \mathrm{C}$ in a Hepes buffer (20 mmol Hepes I ${ }^{-1} ; 25$ mmol L-valine I ${ }^{-1} ; 0.45$ mmol $\mathrm{CaCl}_{2} \mathrm{I}^{-1} ; 100 \mathrm{mmol}$ dithiothreitol $\mathrm{I}^{-1}$ ) containing $0.6 \mu \mathrm{Ci}\left[{ }^{14} \mathrm{C}\right]$ L-arginine $\mathrm{ml}^{-1}$ and $0.5 \mathrm{mmol} \mathrm{NADPH}{ }^{-1}$. After $15 \mathrm{~min}$ of incubation, the samples were centrifuged for $10 \mathrm{~min}$ at $3000 \mathrm{~g}$. The samples were applied to a $1 \mathrm{ml}$ DOWEX AG500-X column ( $\mathrm{Na}^{+}$-form) and $\left[{ }^{14} \mathrm{C}\right] \mathrm{L}$-citrulline was eluted in $3 \mathrm{ml}$ distilled water. The $\left[{ }^{14} \mathrm{C}\right]$ L-citrulline radioactivity was measured by liquid scintillation counting. NOS activity was determined as the difference between $\left[{ }^{14} \mathrm{C}\right] \mathrm{L}$-citrulline produced in the control samples and samples containing $1 \mathrm{mmol}$ EGTA $\mathrm{I}^{-1}$ and 2 mmol L-arginine methyl ester (L-NAME) $\mathrm{I}^{-1}$. Enzyme activity is reported in pmol $\left[{ }^{14} \mathrm{C}\right] \mathrm{L}$-citrulline (100 mg wet weight $)^{-1}$.

\section{Western blot analysis}

Isolated uteri from control and intra-uterine-injected animals were homogenized in $20 \mathrm{mmol}$ Tris buffer $\mathrm{I}^{-1}$ (pH 7.4) containing $1 \mathrm{mmol}$ EDTA I $^{-1}, 2 \mu \mathrm{g}$ aprotinin $\mathrm{ml}^{-1}, 10 \mu \mathrm{g}$ leupeptin $\mathrm{ml}^{-1}, 10 \mu \mathrm{g}$ dithiothreitol $\mathrm{ml}^{-1}$, $100 \mu \mathrm{g}$ soybean trypsin inhibitor $\mathrm{ml}^{-1}, 1 \mathrm{mg}$ caproic acid $\mathrm{ml}^{-1}$ and $1 \mathrm{mg}$ benzamidine $\mathrm{ml}^{-1}$. The homogenates were sonicated (Ultrasonic Cell Disrupter; Microson, Heat systems Inc., Farmingdale, NY) for $30 \mathrm{~s}$ and centrifuged at $1500 \mathrm{~g}$ for $5 \mathrm{~min}$ to remove cellular debris. Protein concentration was determined by the Bradford assay (Bradford, 1976). Each point represents pooled material from four rats. The experiment was repeated three times. Homogenates were boiled for $5 \mathrm{~min}$ in sample buffer $(0.3 \%(\mathrm{w} / \mathrm{v})$ bromophenol blue, $0.5 \mathrm{~mol}$ Tris $\mathrm{I}^{-1}, \mathrm{pH} 6.8,1 \% \quad(\mathrm{w} / \mathrm{v})$ SDS, 5\% (v/v) $\beta$-mercaptoethanol, $10 \%$ (v/v) glycerol). An aliquot $(60 \mu \mathrm{g})$ of total protein was loaded on to each lane. Positive control aliquots were also loaded. Membrane fractions of human endothelial cells, mouse macrophage lysate and rat pituitary lysate were used for eNOS, iNOS and cyclooxygenase 2 , and nNOS, respectively. Samples were subjected to electrophoresis on a $7.5 \%(\mathrm{w} / \mathrm{v})$ Tris ( $\mathrm{pH} 8.8$ )-0.375 mol SDS $\mathrm{I}^{-1}$ polyacrylamide gel $(0.03 \mathrm{~A})$ and transferred to a nitrocellulose membrane (40 V, overnight at $4^{\circ} \mathrm{C}$ ). Membranes were first blocked for $1 \mathrm{~h}$ at room temperature in Tris-saline $(50 \mathrm{mmol}$ Tris- $\mathrm{HCl} \mathrm{I}^{-1}$, $\mathrm{pH} 7.5,500 \mathrm{mmol} \mathrm{NaCl} \mathrm{I}^{-1}$ ) containing
$5 \%(\mathrm{w} / \mathrm{v})$ milk powder, and then incubated overnight at $4^{\circ} \mathrm{C}$ with primary antibodies (mouse antibodies were developed against eNOS, nNOS, iNOS and cyclooxygenase 1, and rabbit antibodies were developed against cyclooxygenase 2). All primary antibodies were used at final dilutions of 1:1000 in Tris-saline buffer. The blots were washed with Tris-saline buffer containing $0.2 \%(\mathrm{w} / \mathrm{v})$ Tween 20. Membranes were incubated for $1 \mathrm{~h}$ at room temperature with the second antibody (goat anti-mouse IgG alkaline phosphatase and goat antirabbit IgG alkaline phosphatase) and washed as above. The developing solution was nitroblue tetrazolium with 5-bromo-4-chloro-3-indol phosphate. Molecular mass standards were run under the same conditions to identify the protein bands. Blots were scanned using a scanning densitometer and the intensity of bands (expressed as relative density) was determined using the Sigma Plot program.

\section{Prostaglandin radioimmunoassays}

PGE and PGF $_{2 \alpha}$ were measured in amniotic fluid samples (Campbell and Ojeda, 1987) obtained from EGF-treated and control rats. In brief, amniotic fluid was removed and frozen until used. Amniotic fluid was acidified to $\mathrm{pH} 3$ with $1 \mathrm{~N} \mathrm{HCl}$ and prostaglandins were extracted twice with $2 \mathrm{ml}$ ethyl acetate. Prostaglandin concentrations were determined by radioimmunoassay. The $\mathrm{PGF}_{2 \alpha}$ antiserum was highly specific and showed low crossreactivity $\left(<0.1 \%\right.$ for $\mathrm{PGE}_{1}$ and $\left.\mathrm{PGE}_{2}\right)$. The PGE antiserum was highly specific for $\mathrm{PGE}_{1}$ and $\mathrm{PGE}_{2}$ and showed low crossreactivity $\left(<0.1 \%\right.$ for $\left.\mathrm{PGF}_{2 \alpha}\right)$. The sensitivity was 5-10 pg per tube and 2-5 $\mu$ l aliquots of amniotic fluid were assayed routinely. Values are expressed as pg prostaglandins (mg wet weight) ${ }^{-1}$.

\section{Progesterone radioimmunoassay}

Progesterone was measured in serum samples (Abraham et al., 1971) extracted from EGF-treated and control rats. In brief, blood was allowed to clot and was centrifuged at $1100 \mathrm{~g}$ for $10 \mathrm{~min}$. The serum was removed and frozen until used. Progesterone was extracted twice with $2 \mathrm{ml}$ diethyl ether and progesterone concentrations were determined by radioimmunoassay. The progesterone antiserum was highly specific for progesterone and showed low crossreactivity $(<2 \%$ for $20 \alpha$-dihydroprogesterone and deoxycorticosterone, and $1 \%$ for other steroids normally found in serum). The sensitivity was 5-10 pg per tube and 2-5 $\mu$ l aliquots of serum were assayed routinely. Values are expressed as pg progesterone $\left(\mathrm{ml}^{-1}\right.$ serum).

\section{Contractility studies}

Each uterine horn (belonging from control and EGFtreated rats) was divided by a transverse cut into two 
Table 1. Effect of intra-uterine administration of epidermal growth factor (EGF) to pregnant rats

\begin{tabular}{|c|c|c|c|c|c|c|c|}
\hline \multirow[b]{2}{*}{$\begin{array}{l}\text { Day of EGF } \\
\text { administration }\end{array}$} & \multicolumn{7}{|c|}{ Dose of EGF administered (ng) } \\
\hline & $\begin{array}{l}\text { Control (saline } \\
\text { solution) }\end{array}$ & 15 & 30 & 60 & 120 & 250 & 500 \\
\hline Day 20 & $1.9 \pm 0.6$ & $1.5 \pm 0.5$ & $1.8 \pm 0.2$ & $2.4 \pm 0.8$ & $2.3 \pm 0.3$ & $12.8 \pm 0.4^{\mathrm{a}}$ & $10.3 \pm 0.3^{\mathrm{a}}$ \\
\hline Day 21 & $2.4 \pm 0.2$ & $2.3 \pm 0.5$ & $2.9 \pm 0.5$ & $1.9 \pm 0.6$ & $9.9 \pm 1.0^{\mathrm{a}}$ & $12.9 \pm 0.8^{\mathrm{ab}}$ & $19.8 \pm 0.7^{\mathrm{cd}}$ \\
\hline Day 22 & $2.8 \pm 0.7$ & $2.5 \pm 0.3$ & $2.6 \pm 0.9$ & $2.6 \pm 0.5$ & $3.3 \pm 0.8$ & $3.1 \pm 0.6$ & $2.5 \pm 0.3$ \\
\hline
\end{tabular}

Values are expressed as the mean \pm SEM ( $n=6$ animals for each treatment) difference $(h)$ in the timing of onset of labour compared with the control rats (parturition: 20:00 h). The differences between means were collectively analysed by a two-way ANOVA followed by a Tukey's multiple comparison test.

${ }^{\mathrm{a}} P<0.01$ versus control; ${ }^{\mathrm{b}} P<0.05$ versus 120 ng EGF; ${ }^{\mathrm{c}} P<0.001$ versus control; ${ }^{\mathrm{d}} P<0.01$ versus 120 and 250 ng EGF.

segments of equal length. The segments were placed in Petri dishes containing KRB at room temperature and constantly gassed with $95 \% \mathrm{O}_{2}-\mathrm{CO}_{2}$. Each segment was immediately opened with a cut along the mesosalpinx insertion. One end was attached to a glass holder and immersed in a tissue chamber filled with $20 \mathrm{ml} \mathrm{KRB}$ $\left(\mathrm{pH} 7.4,37^{\circ} \mathrm{C}\right)$ and continuously gassed. The other end was attached to a strain gauge coupled to an amplifier connected directly to a direct writing oscillograph. After a resting tension of $1 \mathrm{~g}$ was applied to each strip by micrometric devices, isometric developed tension (IDT) and frequency of contractions (FC) were measured. IDT values (expressed in $\mathrm{mg}$ ) were the result of the mean amplitude of all the contractions recorded over a $10 \mathrm{~min}$ period. FC values were obtained as the mean number of contractile cycles analysed during the same period. The experiment was repeated four times.

\section{Statistical analyses}

Statistical analysis was performed using the Instat Program (Graph Pad Software, San Diego, CA). Comparisons between values of groups were performed using one- and two-way ANOVA. Significance was determined using Tukey's multiple comparison test for unequal replicates. All values presented in this study are mean \pm SEM. Differences between means were considered significant at $P=0.05$.

\section{Results}

\section{Effect of intra-uterine administration of EGF on onset of parturition}

Pregnant rats were given a single intra-uterine injection of EGF on day 20, 21 or 22 of pregnancy to determine whether EGF modulates the onset of labour. The doses of EGF used were 15, 30, 60, 120, 250 or $500 \mathrm{ng}$ ( $n=6$ for each treatment). Control rats received an intra-uterine injection of saline solution $(n=6)$. The rats treated with saline solution gave birth on day 22 at 20:00 h, with a variation of approximately $2 \mathrm{~h}$. None of the doses of EGF used had any effect when administered on day 22 of pregnancy (Table 1). Rats treated with EGF $(15,30$ or $60 \mathrm{ng})$ on day 20,21 or 22 gave birth during the night of day 22, as did control rats. EGF (120 ng) administered on day 20 of pregnancy did not affect the onset of labour. In contrast, administration of EGF (250 or $500 \mathrm{ng}$ ) on day 20 of gestation delayed parturition by $12 \pm 0.4$ or $10 \pm 0.3 \mathrm{~h}$, respectively, compared with control rats (the $2 \mathrm{~h}$ difference between these values is not significant. The dose of EGF (120 ng) administered on day 21 of pregnancy was capable of delaying parturition by $9 \pm 0.4 \mathrm{~h}$ compared with control rats. As on day 20 of gestation, administration of $250 \mathrm{ng}$ EGF on day 21 of gestation delayed labour by approximately $12 \mathrm{~h}$, whereas administration of 500 ng EGF delayed labour by $19 \pm 0.6 \mathrm{~h}$ compared with controls. A delay of $19 \mathrm{~h}$ in the onset of parturition is approximately $5 \%$ of the total duration of pregnancy. The difference in delay of onset between the three doses of EGF used was significantly different. These results indicate that rats that received an intra-uterine injection of EGF on day 21 of pregnancy gave birth during day 23 of gestation and that this effect appears to be dose dependent. When the dose of EGF administered was increased, the effect on the delay in onset of labour was more pronounced.

The number of pups delivered was not affected by the EGF treatment. Pups from EGF-treated rats grew at the same rate as did control pups. The body weight of the pups after delivery was not significantly different between groups (control pups: $5.1 \pm 0.1 \mathrm{~g}$; pups from treated rats: $4.9 \pm 0.2 \mathrm{~g})$. Although the treatment with EGF affected the onset of parturition, the duration of labour was the same as for control rats. In addition, the mothers that received EGF fed their pups in the same way as did control rats.

\section{Effect of intra-uterine EGF on uterine prostaglandins and NO synthesis}

As intra-uterine administration of EGF (120, 250 or $500 \mathrm{ng}$ ) on day 21 of gestation appeared to have a dosedependent effect, it was decided to investigate whether EGF was capable of regulating uterine prostaglandin and NO synthesis, which are the principal molecules 
(a)

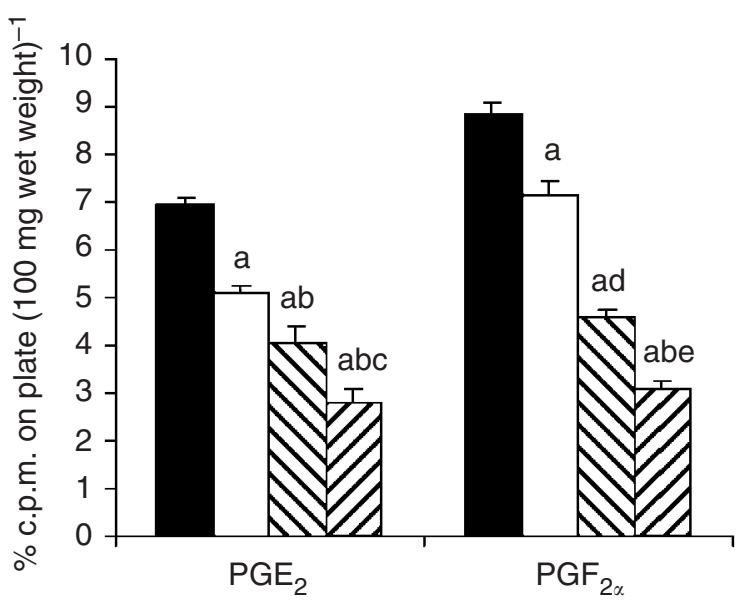

(b)

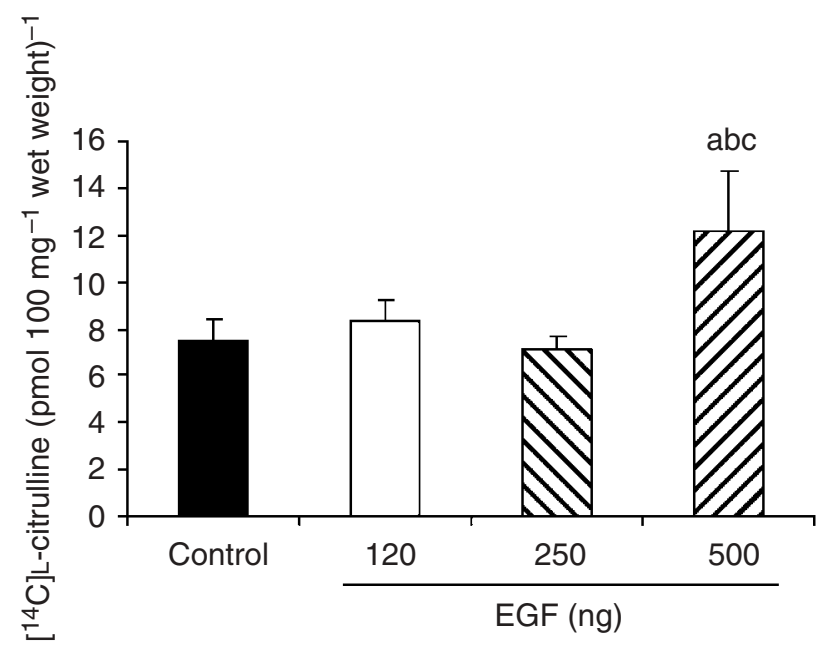

Fig. 1. Effect of intra-uterine administration of epidermal growth

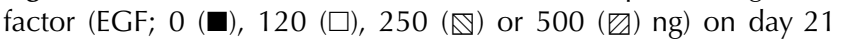
of gestation on (a) prostaglandin and (b) nitric oxide synthesis in rat uterus at day 22 of gestation. Values are mean $\pm \operatorname{SEM}(n=6$ rats per group). The differences between means were collectively analysed by a one-way ANOVA followed by a Tukey's multiple comparison. ${ }^{\mathrm{a} P}<0.001$ versus control; ${ }^{\mathrm{b}} P<0.001$ versus $120 \mathrm{ng}$; ${ }^{\mathrm{c}} P<0.01$ versus $250 \mathrm{ng}$; ${ }^{\mathrm{d}} P<0.05$ versus $120 \mathrm{ng}$; ${ }^{\mathrm{e}} P<0.05$ versus $250 \mathrm{ng}$.

involved in uterine contractility. All animals were killed on day 22 of gestation between 10:00 $\mathrm{h}$ and 11:00 $\mathrm{h}$. The three different doses of EGF administered on day 21 of pregnancy significantly decreased the production of both $\mathrm{PGE}_{2}$ and $\mathrm{PGF}_{2 \alpha}$ compared with control animals (Fig. 1a). The effect of EGF on prostaglandin synthesis was dose dependent, as the inhibitory effect was significantly more pronounced at higher doses of EGF. However, only the highest dose of EGF (500 ng) administered by intra-uterine injection on day 21 of gestation resulted in significant stimulation of $\mathrm{NO}$ production compared with (a)

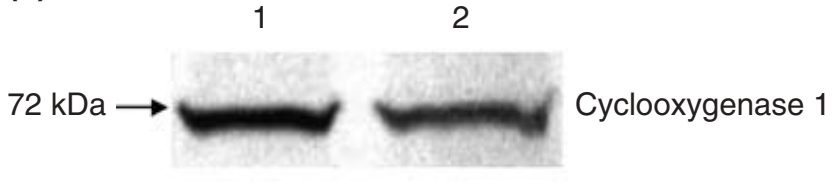

(b)
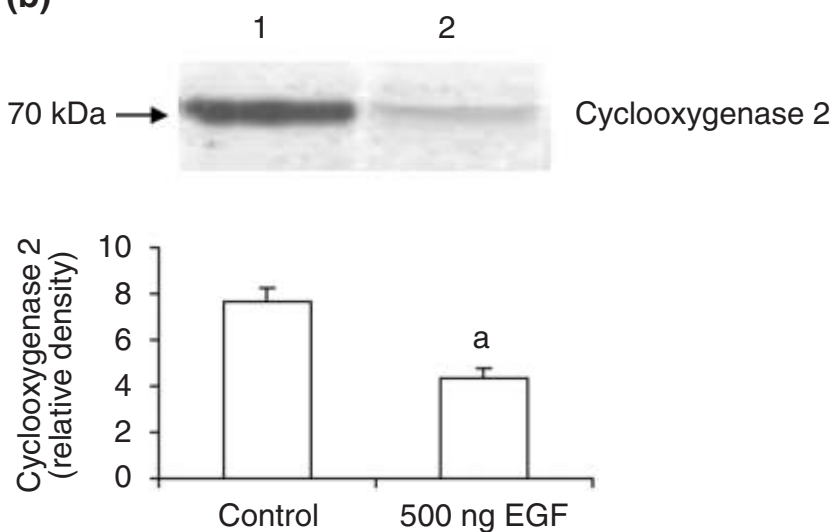

Fig. 2. Effect of intra-uterine administration of epidermal growth factor (EGF; $500 \mathrm{ng}$ ) on day 21 of gestation on (a) cyclooxygenase 1 and (b) cyclooxygenase 2 expression in rat uterus at day 22 of gestation. A representative experiment is shown. The experiment was repeated three times. Values are mean \pm SEM $(n=3$ per group). The differences between means were collectively analysed by a one-way ANOVA followed by a Tukey's multiple comparison. The graph pertains to cyclooxygenase 2 specifically. Data are from western blot analysis. ${ }^{\text {a }} P<0.01$ versus control.

control animals $(P<0.001$; Fig. 1 b). EGF at doses of 120 and $250 \mathrm{ng}$ did not modify NO synthesis. Taking into account the findings that EGF (500 ng) had the strongest effect on the delay of parturition and that it was capable of modifying both prostaglandin and NO production, it was decided to continue the study using this dose.

\section{Effect of intra-uterine EGF (500 ng) on uterine cyclooxygenase and NOS expression}

As production of both prostaglandins and $\mathrm{NO}$ was affected by EGF on day 22 of pregnancy, it was decided to determine whether EGF (500 ng) had an effect on cyclooxygenase-NOS activity, or on its activity and expression. A positive band for cyclooxygenase 1 at an approximate molecular mass of $72 \mathrm{kDa}$ was detected in control and EGF-treated rats (lane 1; Fig. 2a). Expression of cyclooxygenase 1 was not altered by intra-uterine administration of $500 \mathrm{ng}$ EGF on day 21 of gestation (lane 2; Fig. 2a) compared with the control.

Cyclooxygenase 2 was identified as a single band at an approximate molecular mass of $70 \mathrm{kDa}$ in control rats (lane 1; Fig. 2b). Intra-uterine administration of EGF $(500 \mathrm{ng})$ on day 21 resulted in a significant decrease in cyclooxygenase 2 expression $(P<0.01$; lane 2 ; Fig. 2 b). 
(a)

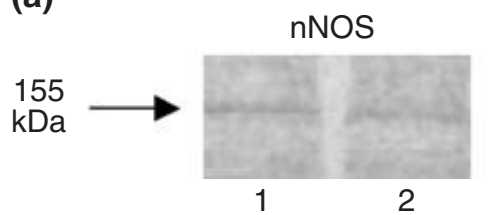

(b)

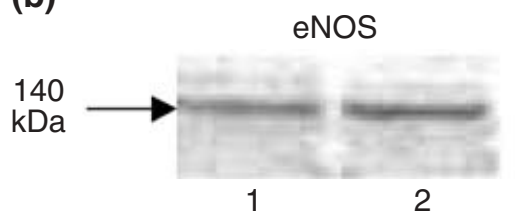

(c)

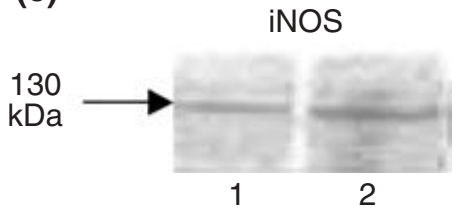

Fig. 3. Effect of intra-uterine administration of epidermal growth factor (EGF; $500 \mathrm{ng}$ ) on day 21 of gestation on (a) nNOS, (b) eNOS and (c) iNOS expression in rat uterus on day 22 of gestation. A representative experiment is shown. Data are from western blot analysis.

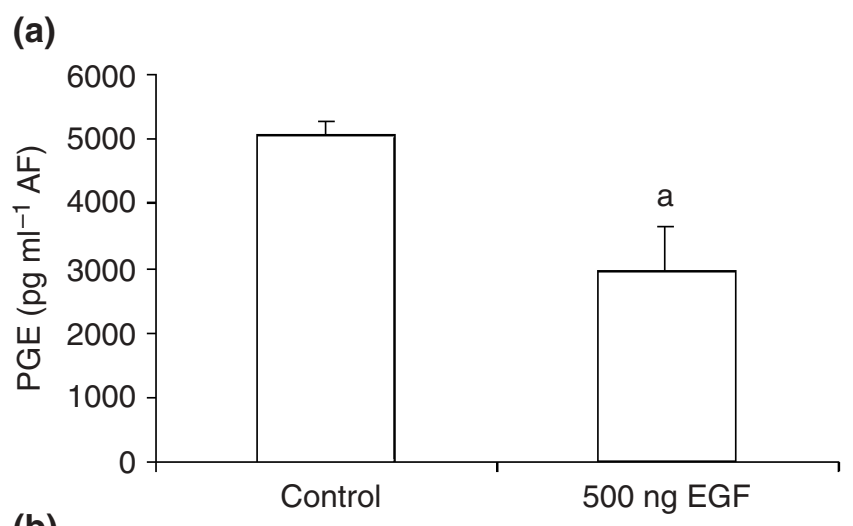

(b)

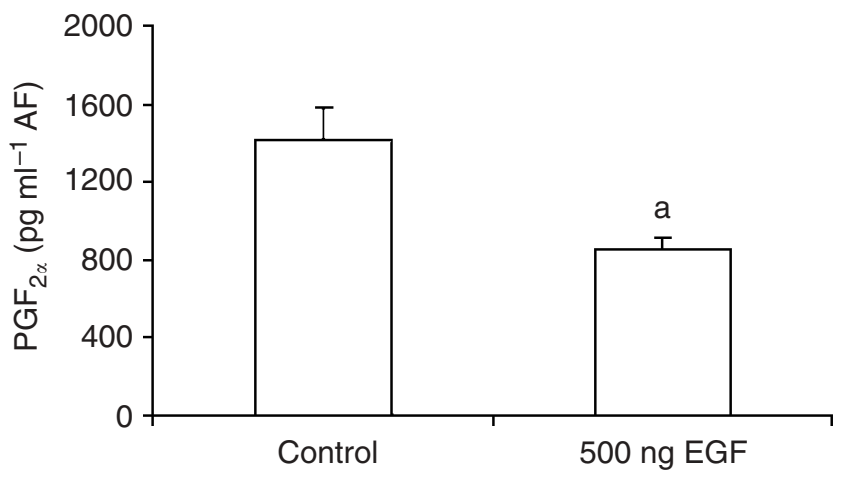

Fig. 4. Effect of intra-uterine administration of epidermal growth factor (EGF; $500 \mathrm{ng}$ ) on day 21 of gestation on (a) prostaglandin $\mathrm{E}_{2}$ $\left(\mathrm{PGE}_{2}\right)$ and $(\mathrm{b})$ prostaglandin $\mathrm{F}_{2 \alpha}\left(\mathrm{PGF}_{2 \alpha}\right)$ concentrations in amniotic fluid (AF) on day 22 of pregnancy. Prostaglandin concentrations were determined by radioimmunoassay. Values are mean \pm SEM ( $n=6$ per group). The differences between means were collectively analysed by a one-way ANOVA followed by a Tukey's multiple comparison. ${ }^{a} P<0.01$ versus control.

The nNOS isoform was barely detectable in the uterine horns obtained from EGF-treated and control pregnant rats (Fig. 3a). It appeared as a single band at approximately $155 \mathrm{kDa}$. There was no difference in the nNOS signal between the control tissue (lane 1; Fig. 3a) and uterine tissue removed from rats that had received an intra-uterine injection of EGF (500 ng) (lane 2; Fig. 3a).

Similar results were observed for eNOS, with the difference that this isoform was readily detected at $142 \mathrm{kDa}$ in the uterine tissue (Fig. 3b). Intra-uterine injection of EGF (500 ng) (lane 1; Fig. 3b) did not

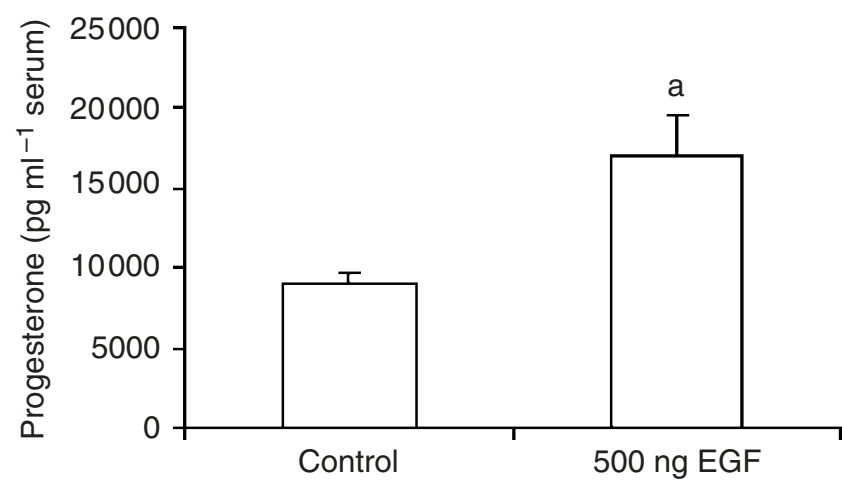

Fig. 5. Effect of intra-uterine administration of epidermal growth factor (EGF; $500 \mathrm{ng}$ ) on day 21 of gestation on serum progesterone concentration at day 22 of pregnancy in rats. Progesterone concentration was determined by radioimmunoassay. Values are mean \pm SEM ( $n=6$ per group). The differences between means were collectively analysed by a one-way ANOVA followed by a Tukey's multiple comparison. ${ }^{\text {a }} P<0.05$ versus control.

modify eNOS expression compared with control uterine tissue (lane 2; Fig. 3b). A positive band for iNOS at an approximate molecular mass of $130 \mathrm{kDa}$ was identified in the uteri of control rats (lane 1; Fig. 3c). Intra-uterine administration of EGF (500 ng) on day 21 of gestation did not affect the expression of iNOS (lane 2; Fig. 3c).

Thus, these results indicate that intra-uterine administration of EGF (500 ng) on day 21 of pregnancy is capable of modifying both prostaglandin synthesis and expression of cyclooxygenase 2. However, EGF (500 ng) affected only NOS activity, as it did not modify expression of any of the NOS isoforms.

\section{Effect of intra-uterine EGF (500 ng) on prostaglandin concentration in amniotic fluid}

As intra-uterine administration of EGF (500 ng) on day 21 of gestation reduced both cyclooxygenase activity and cyclooxygenase 2 expression in the uterus, it was decided to investigate whether the concentration of prostaglandins in amniotic fluid was altered in EGFtreated rats. Intra-uterine administration of EGF (500 ng) on day 21 of gestation significantly decreased the concentration of both $\mathrm{PGE}_{2}$ (Fig. 4a) and $\mathrm{PGF}_{2 \alpha}$ (Fig. 4b) compared with control rats. 
(a)

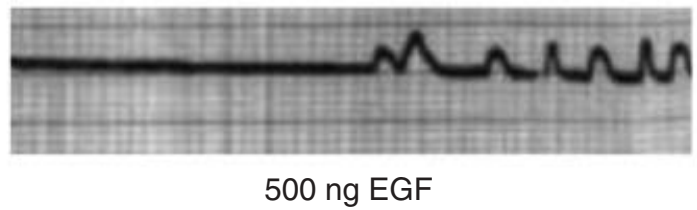

(b)

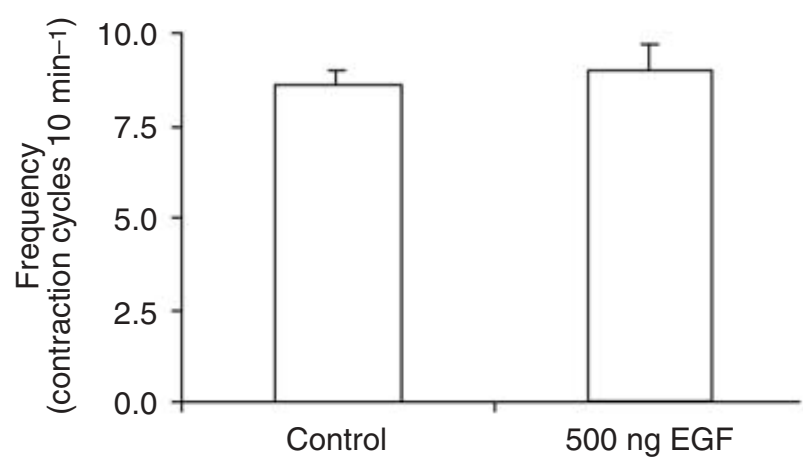

(c)

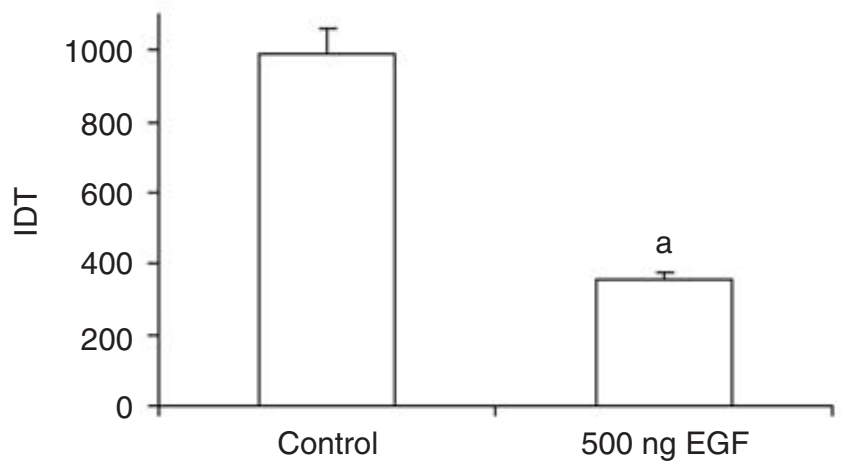

Fig. 6. Effect of intra-uterine administration of epidermal growth factor (EGF; $500 \mathrm{ng}$ ) on day 21 of gestation on (a) spontaneous motility of uterine strips from EGF-treated and control pregnant rats on day 22. (b) Frequency and (c) amplitude of the contractions are shown. IDT values (mean amplitude of all the contractions recorded over a 10 min period) were expressed in mg. Resting applied tension was $1 \mathrm{~g}$. A representative experiment is shown. The experiment was repeated four times. Values are mean \pm SEM $(n=4$ per group). The differences between means were collectively analysed by a one-way ANOVA followed by a Tukey's multiple comparison.

a $P<0.001$ versus control.

\section{Serum progesterone concentrations}

As EGF-treated rats gave birth approximately $18 \mathrm{~h}$ after control animals did, it was decided to investigate whether intra-uterine administration of EGF (500 ng) affected serum progesterone concentrations. Serum progesterone concentrations in rats that received an intra-uterine injection of EGF (500 ng) on day 21 of gestation were twice as high as those of control animals $(P<0.05$; Fig. 5).

\section{Contractility studies}

The study was extended to determine whether administration of exogenous EGF affects myometrial activity. The results of one representative experiment are described below.

Intra-uterine EGF administration was found to modulate uterine contractility (Fig. 6a). Intra-uterine injection of EGF (500 ng) on day 21 of gestation significantly decreased the amplitude of myometrial contractions (IDT) (Fig. 6b): the IDT recorded in treated rats was $60 \%$ lower than the control IDT. However, intra-uterine application of EGF (500 ng) did not modify the frequency of myometrial contractions (Fig. 6c).

\section{Discussion}

The main aim of the present study was to investigate whether in vivo administration of EGF was able to modify uterine contractility, prostaglandin production and timing of parturition in rats. Intra-uterine injection of EGF on day 20 or 21 of pregnancy delayed spontaneous parturition until day 23 of pregnancy. Term delivery usually occurs during the night of day 22. In the present study, it was found that the mechanism underlying the effect of exogenous EGF on onset of parturition was dependent on prostaglandins, $\mathrm{NO}$ and progesterone. To the best of our knowledge, this is the first time that intra-uterine administration of EGF has been reported as an inhibitor of term delivery. It is also worth mentioning that the EGF injection did not alter the general wellbeing of the mother and the pups.

Eicosanoids, particularly prostaglandins, are thought to play a key role in the onset of parturition (Keirse, 1990). Many authors have shown that EGF regulates the expression of cyclooxygenase and the production of prostaglandins in different reproductive tissues. In the present study, it was decided to investigate whether EGF-delayed parturition was mediated by regulation of prostaglandin synthesis. Mitchell (1987) reported that EGF from human and murine sources increased $\mathrm{PGE}_{2}$ production by human amnion cells in culture. Faber et al. (1996) found that the immunostaining of EGF paralleled that of prostaglandins in myometrial tissues obtained from normal human labour. Others have reported that incubation of decidual, amnion and endometrial stromal cells with EGF induced concentration-related increases in $\mathrm{PGE}_{2}$ and $\mathrm{PGF}_{2 \alpha}$ (Casey et al., 1988; Mitchell, 1991; 
Bany and Kennedy, 1995). In the present study, intrauterine administration of EGF $(120,250$ or $500 \mathrm{ng})$ on day 21 of pregnancy inhibited $\mathrm{PGE}_{2}$ and $\mathrm{PGF}_{2 \alpha}$ synthesis. Moreover, the dose-dependent effect on the delay of parturition was paralleled by the inhibition in $\mathrm{PGE}_{2}$ and $\mathrm{PGF}_{2 \alpha}$ production, and the most pronounced effect was caused by administration of 500 ng EGF. Therefore, it is possible that day 21 is pivotal in triggering the signals necessary for the initiation of labour.

NO regulates smooth muscle cell contractility and spontaneous contraction during the oestrous cycle, as well as uterine distension during pregnancy (Franchi et al., 1994; Norman and Cameron, 1996). When the effect of EGF administered on day 21 of gestation was analysed, it was found that EGF (120 or $250 \mathrm{ng}$ ) did not alter NO synthesis compared with that of rats injected with saline solution. However, EGF (500 ng) was able to stimulate the production of $\mathrm{NO}$ compared with that of the control rats. There are not many reports describing an effect of EGF on NO synthesis. A study of Bird et al. (1991) and previous work from our laboratory (Ribeiro et al., 1999) have demonstrated that EGF administration augments NO production in vitro. In support of these results, the highest dose of EGF used in the present study (500 ng) also augmented $\mathrm{NO}$ production in the pregnant uterus. Thus, it is possible that the delay in parturition resulting from intra-uterine administration of EGF was mediated by prostaglandin inhibition and NO stimulation. As EGF (500 ng) had the strongest effect on the delay of parturition and it was the only dose able to modify both prostaglandins and NO, it was decided to continue the study using this dose.

In the next stage of the study we determined whether intra-uterine administration of EGF (500 ng) on day 21 of gestation could modify the uterine expression of the cyclooxygenase and NOS isoforms. At the end of gestation, cyclooxygenase 2 expression is augmented (Bukowski et al., 2001), whereas expression of iNOS decreases (Farina et al., 2001). Western blot analyses showed that intra-uterine EGF (500 ng) inhibited cyclooxygenase 2 expression. Although it was expected that intra-uterine EGF (500 ng) would alter at least iNOS protein, it was found that exogenous EGF did not affect the expression of any of the NOS enzymes. Thus, it appears that intra-uterine EGF (500 ng) administered on day 21 of pregnancy is able to modulate both cyclooxygenase activity and expression, whereas it regulates only NOS activity. Accumulation of fetoplacental-derived prostaglandins in the amniotic fluid during labour may be the means by which these substances reach the myometrium and induce myometrial contractility (Romero et al., 1994; Gibbs and Challis, 2002). EGF is present in human amniotic fluid (Barka et al., 1978), its concentration increases during labour and it stimulates prostaglandin biosynthesis in human amnion and decidua in vitro (Skinner and
Challis, 1985; Mitchell, 1987). Previous observations (Faber et al., 1996), as well as our own, point to the importance of fetoplacental-derived eicosanoids and their possible regulation by growth factors in parturition. The results of the present study show that, as in the case of uterine tissue, the exogenous EGF (500 ng) administered on day 21 of pregnancy decreased the concentrations of both $\mathrm{PGE}_{2}$ and $\mathrm{PGF}_{2 \alpha}$ in the amniotic fluid.

Csapo (1956) showed that plasma progesterone concentration is low at pre-term and normal term labour. The decrease in progesterone concentration triggers uterine changes geared to increase the effectiveness of contractile agonists and also increases the production of the agonists themselves. The present study demonstrates that intra-uterine EGF (500 ng) administered on day 21 of gestation maintains a high concentration of progesterone compared with the concentration in serum extracted from control rats.

The action of intra-uterine EGF (500 ng) on spontaneous uterine contractility in isolated strips was examined to link the effects of EGF on cyclooxygenase, NOS and progesterone to the physiological function of these mediators in the uterus. Intra-uterine EGF (500 ng) had an inhibitory action on the amplitude but not on the frequency of the uterine contractions. This result indicates that intra-uterine EGF is only able to modulate the force of the uterine contractions. One possibility is that this is an after effect of the decreased prostaglandin synthesis and augmented NO production in the uterine tissue. The other possibility is that intra-uterine EGF (500 ng) exerts its action directly on the contraction mechanism, as rat uterine tissue expresses EGF receptors (Lin et al., 1988). Gardner et al. (1987) reported that EGF in vitro produces uterine contractions in tissues removed from immature and adult ovariectomized oestrogentreated rats. The difference from our results could be due to the different experimental models used. The results reported by Tamada et al. (2000) support our findings, as they found that intraluminal infusion of EGF into goat uterine horns gradually reduced the uterine activity at either oestrus or dioestrus. One of the questions that must be answered is which cells within the uterine tissue are responsible for producing EGF. The study of Kusakabe et al. (1999) demonstrates that murine uterine natural killer cells are immunohistochemically positive for anti-EGF antibody, especially at days 6-9 and at day 15 of pregnancy. This result indicates that in murine pregnant uterus the large granular lymphocyte cells may be responsible for EGF secretion. More studies are being performed in our laboratory to determine which uterine cells are involved in the secretion of EGF during pregnancy in rats.

In conclusion, we present an animal model in which it is possible to study post-term delivery and the regulation of important mediators of pregnancy and parturition such as prostaglandins, $\mathrm{NO}$ and progesterone. 
The authors would like to thank R. Morales and A. Inés Casella for their technical support. The authors would also like to thank $\mathrm{V}$. Rettori for her constructive criticism of the manuscript. This work was supported by FONCYT (PICT 98/05-04426).

\section{References}

Abraham GE, Swerdloff R, Tulchinaky D and Odell WD (1971) Radioimmunoassay of plasma progesterone Journal of Clinical Endocrinology 32 $619-624$

Ances IG (1973) Serum concentrations of epidermal growth factor in human pregnancy American Journal of Obstetrics and Gynecology 115 357360

Bany BM and Kennedy TG (1995) Regulation by epidermal growth factor of prostaglandin production and cyclooxygenase activity in sensitized rat endometrial stromal cells in vitro. Journal of Reproduction and Fertility 104 57-62

Barka T, Vander Noen H, Gresik EW and Kerenyi T (1978) Immunoreactive epidermal growth factor in human amniotic fluid Mount Sinai Journal of Medicine 45 679-682

Bird IM, Sullivan JA, Di T, Cale JM, Zhang L, Zheng J and Magness RR (1991) Pregnancy-dependent changes in cell signaling underlie changes in differential control of vasodilator production in uterine artery endothelial cells Endocrinology 141 1107-1117

Bradford M (1976) A rapid and sensitive method for the quantitation of microgram quantities of protein utilizing the principle of protein-dye binding Analytical Biochemistry 72 246-254

Bredt DS and Snyder SH (1987) Nitric oxide mediates glutamate-linked enhancement of cGMP levels in the cerebellum Proceedings National Academy of Sciences USA 86 9030-9033

Bukowski R, McKay L, Shi S, Saad GR and Garfield RE (2001) The effects of cervical application of inhibitors of inducible nitric oxide synthase, cyclooxygenase- 1 and cyclooxygenase- 2 on delivery in rats American Journal of Obstetrics and Gynecology $185959-$ 965

Campbell WB and Ojeda SR (1987) Measurement of prostaglandins by radioimmunoassay Methods in Enzymology 141 323-341

Casey LM, Korte K and McDonald $\mathbf{P}$ (1988) Epidermal growth factor stimulation of prostaglandin $\mathrm{E}_{2}$ biosynthesis in amnion cells Journal of Biological Chemistry 263 7846-7854

Cohen S (1962) Isolation of a mouse submaxillary protein accelerating incisor eruption and eyelid opening in the newborn animal Journal of Biological Chemistry 237 1555-1561

Csapo A (1956) Progesterone block American Journal of Anatomy 98 273292

Das H, Tsukamura H, Paria BC, Andrews GK and Dey SK (1994) Differential expression of epidermal growth factor receptor (EGF-R) gene and regulation of EGF-R bioactivity by progesterone and estrogen in the adult mouse uterus Endocrinology 134 971-981

Faber BM, Metz SA and Chegini N (1996) Immunolocalization of eicosanoid enzymes and growth factors in human myometrium and fetoplacental tissues in failed labor inductions Obstetrics and Gynecology 88 174179

Farina M, Ribeiro ML and Franchi A (2001) Nitric oxide synthases in pregnant rat uterus Reproduction 121 403-407

Franchi AM, Chaud M, Rettori V, Suburo A, McCann S and Gimeno M (1994) Role of nitric oxide in eicosanoid synthesis and uterine motility in estrogen-treated rat uteri Proceedings National Academy of Sciences USA 91 539-543

Gardner RM and Stancel GM (1989) Blockade of epidermal growth factorinduced uterine contractions by indomethacin or nordihydroguaritic acid Journal of Pharmacological and Experimental Therapies 250882 886

Gardner RM, Lingham RB and Stancel GM (1987) Contractions of the isolated uterus stimulated by epidermal growth factor FASEB Journal $1224-228$
Gibbs W and Challis JR (2002) Mechanisms of term and preterm birth Journal of Obstetrics and Gynaecologic Cancer 24 874-883

Huet-Hudson YM, Chakraboty C, De SK, Suzuki Y, Andrews GK and Dey SK (1990) Estrogen regulates epidermal growth factor in mouse uterine epithelial cells Molecular Endocrinology 4 510-523

Keirse $\mathbf{M}$ (1990) Eicosanoids in human pregnancy and parturition. In Eicosanoids in Reproduction pp 199-222 Ed. M Mitchell. CRC Press, Boca Raton

Kujubu DA, Fletcher BS, Varnum BC, Lin RW and Hersham HR (1991) Tis 10, a phorbol ester tumor promoter inducible mRNA from Swiss 3T3 cells, encodes a novel prostaglandin synthase/cyclooxygenase homologue Journal of Biological Chemistry 26612 866-12 878

Kusakabe K, Ohmoto M, Okada T, Mukamoto M, Sasaki F and Kiso Y (1999) Uterine natural killer cells produce epidermal growth factor in the murine pregnant uterus Journal of Veterinary Medical Science $\mathbf{6 1}$ 947-949

Lacroix MC and Kann G (1993) Ontogeny and characterization of epidermal growth factor receptors on the fetal area of the sheep placenta Journal of Endocrinology 136 43-50

Lin TH, Verner G, Kirkland JL and Stancel GM (1988) Autoradiographic localization of epidermal growth receptors to all major uterine cell types Biology of Reproduction 38 403-411

Maruo T, Matsuo H, Oishi T, Hayashi M, Nishini R and Mochizuki M (1987) Induction of differentiated trophoblast function by epidermal growth factor: relation of immunohistochemically detected cellular epidermal growth factor levels Journal of Clinical Endocrinology and Metabolism 64 744-752

Mitchell M (1987) Epidermal growth factor actions on arachidonic acid metabolism in human amnion cells Biochimica et Biophysica Acta 928 240-242

Mitchell M (1991) The regulation of decidual prostaglandin biosynthesis by growth factors, phorbol esters and calcium Biology of Reproduction $\mathbf{4 4}$ 871-874

Mitchell MD, Romero RJ, Edwin SS and Trautman MS (1995) Prostaglandins and parturition Reproduction, Fertility and Development 7 623632

Norman J and Cameron L (1996) Nitric oxide in the human uterus Reviews of Reproduction 1 61-68

Perkins DJ and Kniss DA (1999) Blockade of nitric oxide formation downregulates cyclooxygenase- 2 and decreases $\mathrm{PGE}_{2}$ biosynthesis in macrophages Journal of Leukocyte Biology 65 792-799

Ribeiro ML, Perez Martinez S, Ogando D, Farina M and Franchi A (1999) The effect of epidermal growth factor on prostaglandin synthesis of oestrogenized rat uterus is mediated by nitric oxide Prostaglandins, Leukotrienes and Essential Fatty Acids 61 353-358

Richards RC, Beardmore JM, Brown PJ, Molloy CM and Johnson PM (1983) Epidermal growth factor receptors on isolated human placenta syncyotiotrophoblast plasma membrane Placenta 4 133138

Romero R, Baumann P, Gonzalez R, Gomez R, Rittenhouse L, Behnke E and Mitchell MD (1994) Amniotic fluid prostanoid concentrations increase early during the course of spontaneous labor at term American Journal of Obstetrics and Gynecology 171 1613-1620

Salvemini D, Misko TP, Masferrer JL, Seibert K, Currier MG and Needleman M (1996) Nitric oxide activates cyclooxygenase enzymes Proceedings National Academy of Sciences USA 90 7240-7249

Skinner KA and Challis JR (1985) Changes in the synthesis and metabolism of prostaglandins by human fetal membranes and deciduas at labor American Journal of Obstetrics and Gynecology 151519 523

Simmons DL, Xie W, Evett G, Merrill J, Roberton DL and Bradshaw WS (1993) Drug inhibition and cellular regulation of prostaglandin $\mathrm{G} / \mathrm{H}$ synthase isoenzyme 2 Journal of Lipid Mediation 6 113-117

Tamada H, Yoh C, Inaba T, Takano H, Kawate N and Sawada T (2000) Epidermal growth factor (EGF) in the goat uterus: immunohistochemical localization of EGF and EGF receptor and effect of EGF on uterine activity in vivo. Theriogenology 54 159-169

Varner MW, Dildy GA, Hunter C, Dudley DJ, Clark SL and Mitchell D (1996) Amniotic fluid epidermal growth factor levels in normal and 
abnormal pregnancies Journal of Society of Gynecological Investigation 3 17-19

Vaughan TJ, Littlewood CJ, Pascall JC and Brown KD (1992) Epidermal growth factor concentrations in pig tissues and body fluids measured using a homologous radioimmunoassay Journal of Endocrinology 135 77-83

Yallampalli C, Garfield R and Byam Smith M (1993) An L-arginine-nitric oxide cyclic guanosine monophosphate system exists in the uterus and inhibits contractility during pregnancy Endocrinology 133 1899_ 1902
Yallampalli C, Izumi H, Byam Smith M and Garfield R (1994) Nitric oxide inhibits uterine contractility during pregnancy but not during delivery American Journal of Obstetrics and Gynecology 170 175-185

Received 14 March 2003.

First decision 21 May 2003.

Revised manuscript received 26 June 2003.

Accepted 3 July 2003. 